\title{
Intravenous leiomyomatosis extending into right heart: A case report
}

\author{
Sağ kalbe uzanan intravenöz leiomiyomatozis: Olgu sunumu

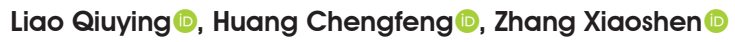 \\ Department of Cardiovascular Surgery, The First Affiliated Hospital, Jinan University, Guangzhou, China
}

\begin{abstract}
Intravenous leiomyomatosis is a rare and special tumor which is exclusively seen in premenopausal women. Herein, we present a 46-year-old female case diagnosed with intravenous leiomyomatosis through an exploratory sternotomy and pathological examination.

Keywords: Cardiac pathology, exploratory sternotomy, inferior vena cava, intravenous leiomyomatosis.
\end{abstract}

Intravenous leiomyomatosis (IVL) is a rare, but benign tumor of the uterus, growing in the inferior vein. In some cases, it can extend into the right-sided cardiac chambers and may cause sudden death. Due to the rarity and its diverse clinical manifestations, IVL may be misdiagnosed or overlooked. ${ }^{[1]}$

In medicine, patient management decisions are usually based on the evidences available for use of a particular investigation or technology or surgical procedure. The hierarchical rank of the evidence signifies the probability of bias. Nevertheless, case reports provide important data for rare events and may be considered as anecdotal evidence. These reports may also prompt the generation of new hypotheses and techniques and, thus, may support the emergence of new researches.

Herein, we present a female case diagnosed with IVL through an exploratory sternotomy and pathological examination and discuss its symptoms, diagnostic tools, surgical procedure, and postoperative follow-up.

\section{$\ddot{O} Z$}

İntravenöz leiomiyomatozis bilhassa premenopozal kadınlarda görülen nadir ve özel bir tümördür. Bu yazıda, keşifsel sternotomi ve patolojik inceleme ile intravenöz leiomiyomatozis tanısı konan 46 yaşında bir kadın olgu sunuldu.

Anahtar sözcükler: Kardiyak patoloji, keşifsel sternotomi, inferior vena kava, intravenöz leiomiyomatozis.

\section{CASE REPORT}

A 46-year-old female patient presented with dyspnea on exertion and palpitation. An echocardiographic examination (Figure 1a) and computed tomography (CT) revealed a tumor originating from the right iliac vein, across the inferior vena cava (IVC) into right atrium (Figure 1b), and entering into the tricuspid valve with cardiac diastole. A normal level of serumbased tumor markers and contrast-enhanced CT scan showed a non-enhancing mass, suggesting a very low possibility of malignancy. Additionally, suspected thrombosis was questionable in this patient, of whom the clinical laboratory values were normal with no potential risk factors except for age and no history of thrombotic disease. Due to recurrent dyspnea during hospitalization, we decided to perform an elective surgery with median sternotomy to prevent deterioration or sudden death. A written informed consent was obtained from the patient.

To establish cardiopulmonary bypass (CPB), femoral vein and superior vena caval cannulation was

Received: November 14, 2019 Accepted: January 31, 2020 Published online: April 22, 2020

Correspondence: Zhang Xiaoshen, MD. Department of Cardiovascular Surgery, The First Affiliated Hospital, Jinan University, 510000 Guangzhou, China. Tel: 86-20-38688612 e-mail: 13726892367@163.com 

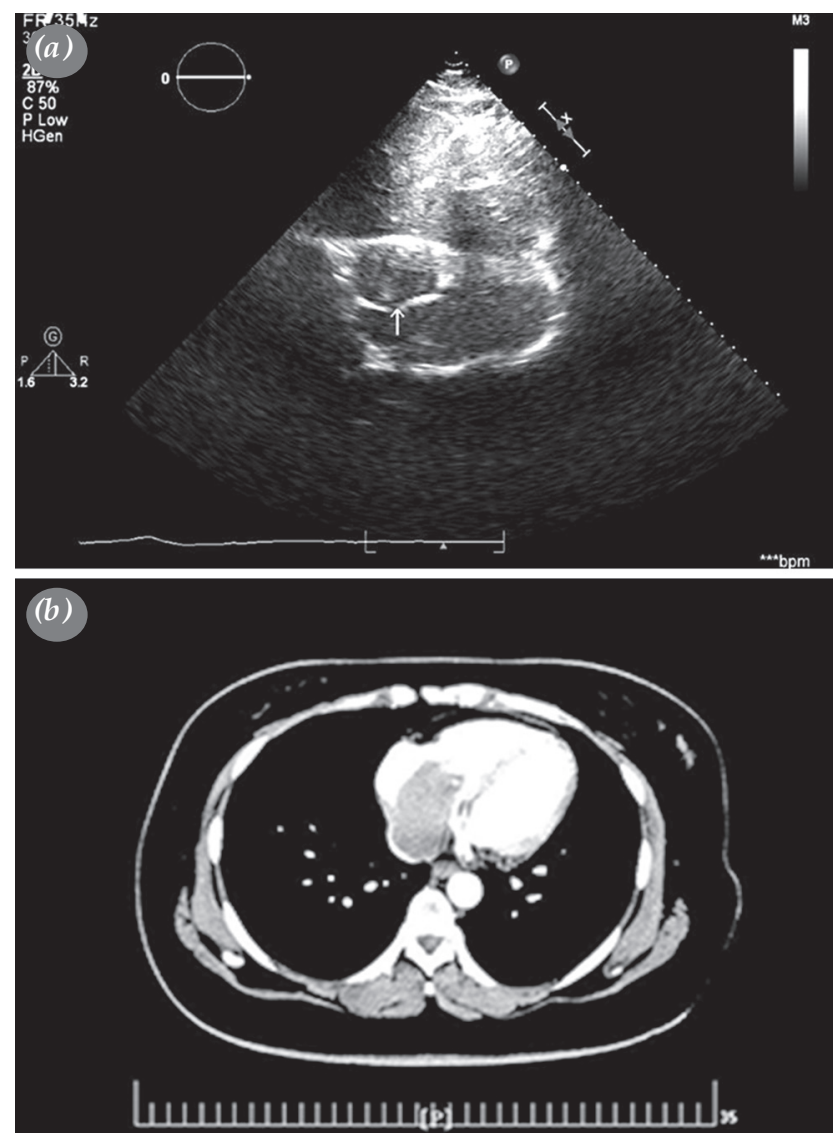

Figure 1. (a) A hyperechoic mass (white arrows) extending from right atrium to right ventricle through tricuspid valve. (b) An axial image of a contrast-enhanced heart and pelvic computed tomography scan. Hypoattenuating intraluminal material within heart.

used. A grey solid mass was revealed during surgical exploration, extending from the IVC into the right atrium. During the procedure, the catheter was able to be accessed into the IVC via femoral vein carefully to ensure that the IVC was not obstructed, but the mass was solid. The tumor was pulled out slowly due to

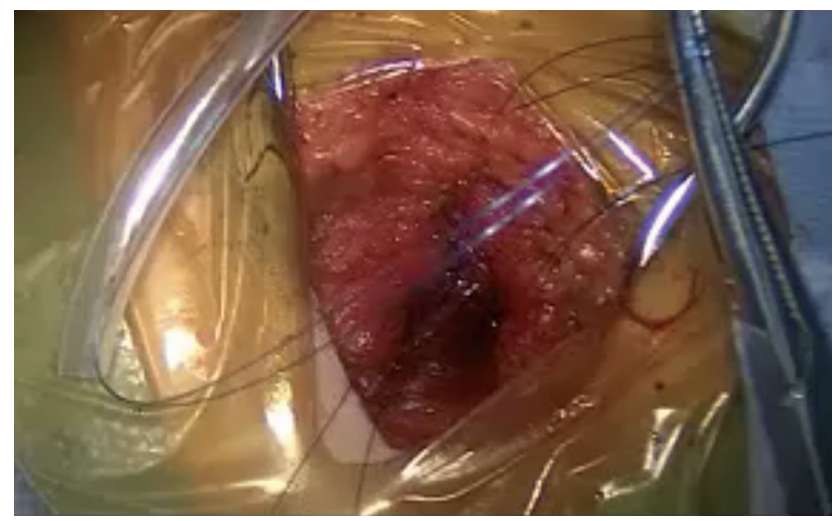

Video 1. Video of the operation.
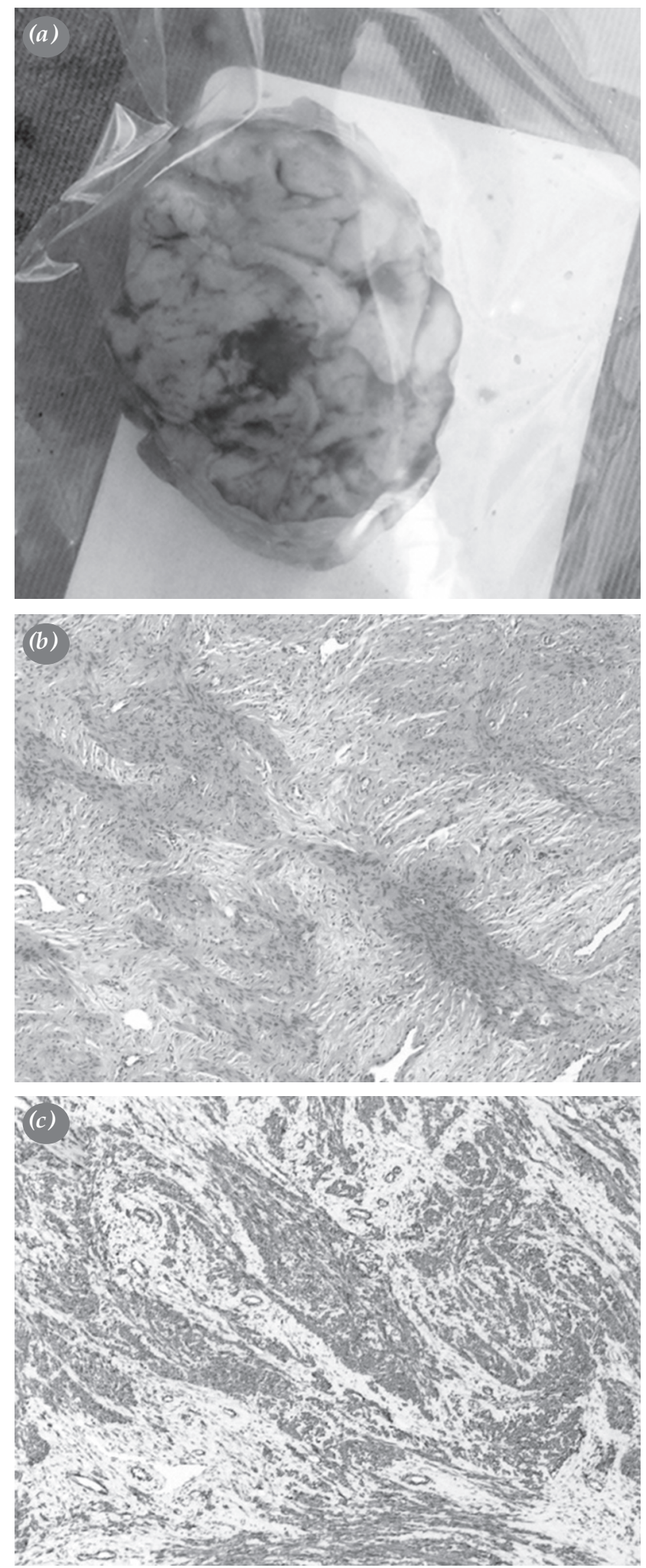

Figure 2. (a) Part of the tumor resected during surgery. (b) The tumor arranged in an orderly manner by spindle cells with a uniform size $(\mathrm{H}-\mathrm{E} \times 40)$; (c) Tumor cell cytoplasm positive for SMA $(\mathrm{H}-\mathrm{E} \times 40)$.

SMA: Smooth muscle actin; H-E: Hematoxylin-eosin. 

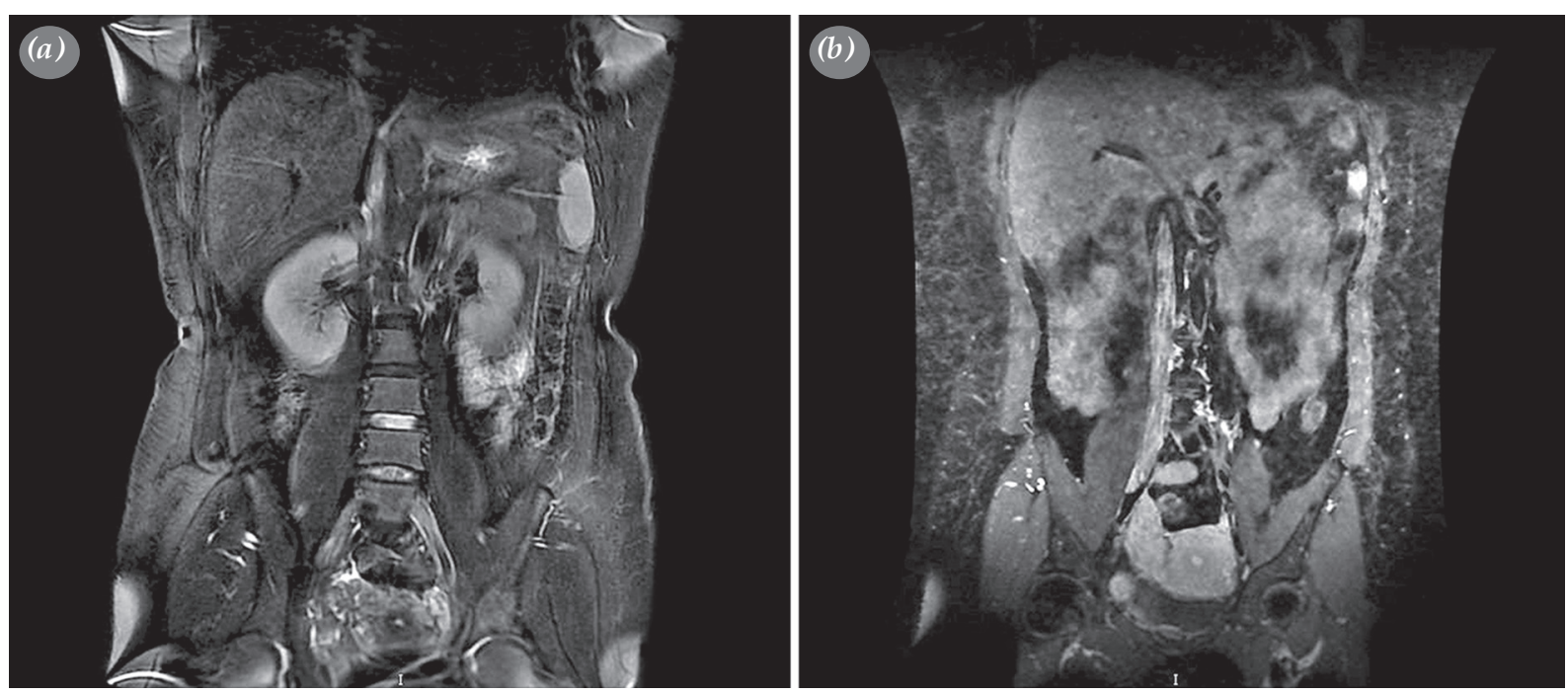

Figure 3. (a) Control magnetic resonance imaging after cardiac tumor resection showing no recurrence. (b) Control magnetic resonance imaging after cardiac tumor resection showing the presence of intravenous leiomyomatosis in inferior vena cava.

its firmly adhered nature to the adjacent tissues and stripped to the orifice of IVC (Video 1).

The result of histopathological examination confirmed IVL, compatible with the frozen-section results. Immunohistochemistry revealed that the cells were positive for desmin and smooth muscle actin (SMA), but negative for CD117, DOG-1, and S-100. The positive rate of $\mathrm{Ki}-67$ was less than $5 \%$, and the electropositive rate of estrogen receptor (ER) and progesterone were $80 \%$ and $90 \%$, respectively

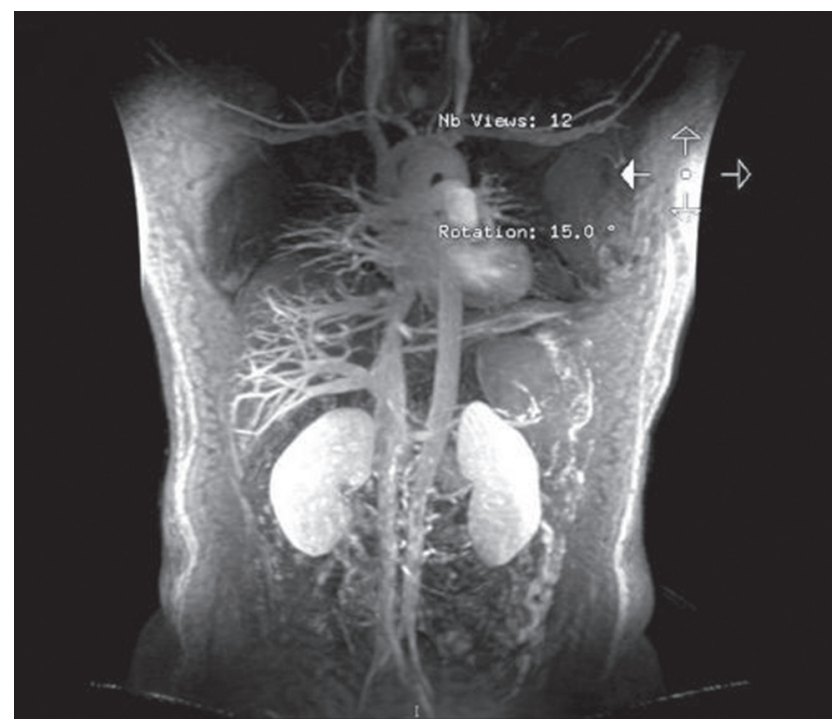

Figure 4. Control magnetic resonance imaging after second stage surgery showing no intravenous leiomyomatosis in inferior vena cava or heart.
(Figure 2a-c). On the basis of pathological results, the definite diagnosis was made and the next stage operation was planned. The patient recovered smoothly in the postoperative period and uneventfully discharged from the hospital (Figure 3a, b). She underwent secondstage surgery after six months (Figure 4). Both uterine adnexa and IVL located in the IVC were resected with an abdominal incision. No recurrence of tumor was observed during follow-up.

\section{DISCUSSION}

Intravenous leiomyomatosis is a benign neoplasm and involves the right heart and lungs, similar to malignant tumors. Once IVL invades the heart, patients may suffer from congestive heart failure with palpitation, dyspnea on exertion, pulmonary embolism, or even sudden death. ${ }^{[2]}$ A thorough resection of the tumor is the key to prevent recurrence. ${ }^{[3]}$

Exploration is essential to unravel diagnosis and remove life-threatening lesions safely. In this case, a right atrial active mass had a potential risk of pulmonary embolism or even sudden death and the preoperative examination findings and symptoms were not suggestive of the definite diagnosis; therefore, exploration was required. After exposing the heart by median thoracotomy, we established moderate CPB by aortic cannula and superior vena cava drainage to ensure hemodynamic stability. Compared to the IVC intubation, femoral venous cannulation can provide a better view of the inferior vena and right atrium (femoral vein drainage tube can track back, if necessary), which helps to explore the nature of the 
mass when it extends into the inferior vena. Using femoral venous cannulation, we confirmed that the IVC was not obstructed and the tumor was so tenacious that it did not tend to exfoliation easily, leading to pulmonary embolism. This was the first attempt through femoral venous cannulation during exploration of the IVC.

In the present case, pathology was the major evidence for the diagnosis. Histopathological examination was also needed to confirm the mass property and origin, directly leading us to the next step of treatment and surgery. We decided to apply combined staged operation after frozen-section biopsy. Of note, as leiomyoma is a benign tumor originating from the uterus, it requires a multidisciplinary approach for radical cure and incomplete resection does not induce tumor spread.

It has been reported that high levels of estrogen affect the occurrence and development of IVL. ${ }^{[4]}$ The tumor is sensitive to ER based on the immunohistochemical findings. An anti-estrogen therapy has been suggested as a reasonable approach to control unresectable tumors. ${ }^{[4,5]}$ However, our case refused anti-estrogen therapy.

Furthermore, follow-up is of utmost importance, as IVL has a high rate of recurrence after the operation. Echocardiographic, magnetic resonance imaging, and $\mathrm{CT}$ are the main tools for postoperative examination. Increased recognition of IVL may also help to promote the diagnostic rate and facilitate early detection of recurrence.
In conclusion, exploratory sternotomy and pathological examination are the cornerstones for the diagnosis of this rare disease. We believe that accumulation of additional cases would provide a better understanding of the diagnosis and treatment of intravenous leiomyomatosis.

\section{Declaration of conflicting interests}

The authors declared no conflicts of interest with respect to the authorship and/or publication of this article.

\section{Funding}

This study was financially supported by the Science and Technology Planning Project of Guangdong Province, China [2017A020215076].

\section{REFERENCES}

1. Kocica MJ, Vranes MR, Kostic D, Kovacevic-Kostic $\mathrm{N}$, Lackovic $\mathrm{V}$, Bozic-Mihajlovic $\mathrm{V}$, et al. Intravenous leiomyomatosis with extension to the heart: rare or underestimated? J Thorac Cardiovasc Surg 2005;130:1724-6.

2. Lam PM, Lo KW, Yu MY, Wong WS, Lau JY, Arifi AA, et al. Intravenous leiomyomatosis: two cases with different routes of tumor extension. J Vasc Surg 2004;39:465-9.

3. Leitman M, Kuperstein R, Medalion B, Stamler A, Porat E, Rosenblatt $S$, et al. A highly unusual right atrial mass presented in two women. Eur J Echocardiogr 2008;9:833-4.

4. Du J, Zhao X, Guo D, Li H, Sun B. Intravenous leiomyomatosis of the uterus: a clinicopathologic study of 18 cases, with emphasis on early diagnosis and appropriate treatment strategies. Hum Pathol 2011;42:1240-6.

5. Morales MM, Anacleto A, Leal JC, Carvalho S, Del'Arco J. Intravascular leiomyoma with heart extension. Clinics (Sao Paulo) 2012;67:83-7. 